\title{
INFLUENCE OF FUEL FLOW RATE VARIATION ON MOLTEN SALT REACTOR PERFORMANCE
}

\author{
Negri $\mathrm{O}^{1}$ and Abram $\mathrm{T}^{1}$ \\ ${ }^{1}$ The University of Manchester \\ School of Mechanical, Aerospace and Civil Engineering, F floor, G1, Pariser Building, The \\ University of Manchester, Sackville Street, Manchester, M13 9PL \\ Olga.negri@manchester.ac.uk, Timothy.Abram@manchester.ac.uk
}

\begin{abstract}
Molten Salt Reactors are Gen-IV reactors that use liquid fuel. Fluid fuel allows continuous removal of fission gases as well as batch fuel reprocessing. With these control mechanisms the system can be sustained within the desired operating temperature range and required power output. These methods rely on the presence of a chemical processing plant on-site that adds complexity. This also creates a risk of processing plant unavailability due to faults, emergency downtime or maintenance. The work considers variation of fuel salt flow rate in Molten Salt Reactors as a means of controlling reactor operation without using reprocessing. The analysis is performed using the Molten Salt Fast Reactor as an example. An extended version of the SERPENT Monte-Carlo transport code coupled with OpenFOAM generic platform were used for capturing delayed neutron drift, decay heat, gaseous fission product removal, calculating fuel salt velocity vectors and the fuel temperature distribution. The two models were coupled via a script that accounted for reactivity insertion between time steps and the changes caused in the fission power. Results confirm that, while operating at constant power, the difference between fuel inlet and outlet temperatures increase as the flow rate decreases. Burnup analysis has shown that while the average fuel temperature continues to reduce with time, the difference between inlet and outlet temperatures can be controlled by varying the flow rate while maintaining constant power. Finally, the variation in the fuel flow rate has been shown to extend the reactor operating time with no insertion of additional fissile inventory.
\end{abstract}

KEYWORDS: Molten Salt Reactor, Molten Salt Fast Reactor, control, Monte-Carlo, thermal-hydraulics

\section{INTRODUCTION}

Molten Salt Reactors (MSRs) are one type of the Generation IV reactors [1]. The concept originates from the Aircraft Reactor Experiment in Oak Ridge National Laboratory [2]. The MSR use molten salt as the fuel that, in majority of the designs [3]-[9], is circulated between the core and the heat exchangers. Due to a liquid state of the fuel of the MSR control can be performed by means of on-line removal of fission gases via helium bubbling, batch removal of lanthanides via pyrochemical reprocessing (at rate of 40 1/day for the MSFR) and continuous addition of fissile materials [3]-[9]. Furthermore, some of the MSRs rely on the negative temperature coefficient [10] and are proposed to operate without control rods.

There are several challenges connected to MSR control via reprocessing. Continuous refuelling implies a continuous supply of fresh fissile inventory and fuel reprocessing requires handling extracted fission products. Moreover, in the event of a failure of the chemical plant or unavailability of fresh fissile isotopes, 
criticality control relies on the negative temperature coefficient of reactivity. In the event of lack of fissile material or reprocessing plant down-time the temperature will be decreasing. As it decreases, the fissile material will continue to be consumed. Eventually the temperature could drop below the solidification point.

This study investigates if the MSR control can be performed by varying the parameters that are independent from fuel salt reprocessing, such as pump rate. The Molten Salt Fast Reactor (MSFR) model is used to test this concept. The study involves coupled neutronics and thermal-hydraulics analyses. The analyses were performed for steady state and transient events when the flow rate of the salt was increased or decreased from normal values.

\section{BACKGROUND}

The MSFR is a MSR design developed during the Safety Assessment of the Molten Salt Fast Reactor (SAMOFAR) project. The MSFR design was chosen during this study because its modelling requires consideration of the main areas of interest common for most of the MSR designs such as on-line gaseous fission product removal, assessment of thermal-hydraulics and delayed neutron behaviour.

The MSFR is a homogeneous single fluid concept with circulating fuel salt. The reactor includes a nonmoderated core of $1.25 \mathrm{~m}$ radius, $2.5 \mathrm{~m}$ height and 16 heat exchanger loops which allow the fuel salt to be transferred to the heat exchangers and to the reprocessing plant [11], [12], see Figure 2.1. The MSFR Figure 2.1. Pumps located in each heat exchanger loop near the core inlet are designed to circulate the fuel salt at flow rate of $3.61 \mathrm{~m} / \mathrm{s}$ (further: nominal flow rate). The fuel salt composition is $\mathrm{LiF}_{-} \mathrm{UF}_{4}-\mathrm{ThF}_{4}$ with $22.5 \%$ of heavy nuclei, $3 \% \mathrm{U}^{233}$, the salt density at $900 \mathrm{~K}$ was assumed to be $4.3 \mathrm{~g} / \mathrm{cm}^{3}$.

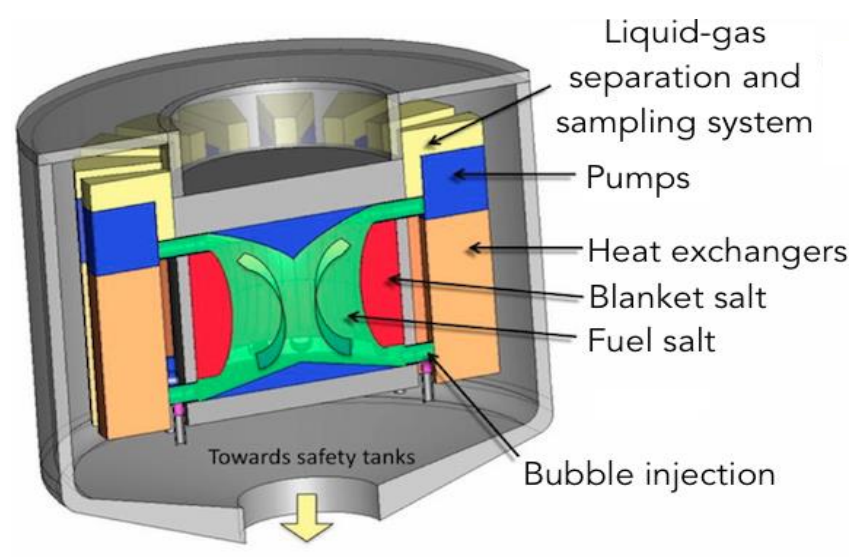

Figure 2.1. The MSFR [13]

During the circulation gaseous fission products, in particular noble gases, are removed from the fuel salt by helium bubbling [9]. Some of the isotopes are unstable and would normally contribute towards the decay heat. However, in this case this fraction of the decay heat would be lost to the core. The remaining of the decay heat would be distributed in the fuel salt. The distribution would depend on the decay location of the decay heat precursors. Similarly, delayed neutron precursors also drift from the core. Part of these precursors will decay in the heat exchangers and would be lost to the total neutron population.

Fuel salt temperature increases when the salt passes through the core due to fission reactions. At a higher flow rate the fuel salt spends less time in the core and less time in the heat exchangers, therefore the temperature difference between the inlet and the outlet is reduced for the same power output. Combined 
with the negative temperature coefficient, this can enable to control fuel temperature without the use of a chemical plant.

\section{METHODOLOGY}

\subsection{SERPENT extension}

For the neutronics calculations the three-dimensional continuous-energy Monte Carlo reactor physics burnup calculation code SERPENT-2 was used. The code has been under development at the VTT Technical Research Centre of Finland since 2004 [14]. The JEFF-3.1.1 data library is used for the neutronics calculations. An extension of the code was created in order to account for delayed neutron loss in heat exchangers based on the delayed neutron precursor decay time and fuel salt axial velocity.

The methodology used in this study is similar to that suggested by Aufiero M. [15]. In order to reduce the computational cost the SERPENT extension suggested in this study allows modeling only the reactor core in contrary to [15] where heat exchangers are also modeled.

In the SERPENT neutronics code sampling of delayed neutrons is modelled by allocating precursor's group half-life, precursor decay time and coordinates. The extension starts by reading the precursor coordinates and emission time $\left(\mathrm{t}_{\mathrm{e}}\right)$. Then local velocity vectors are read and new coordinates are calculated. The extension checks if the coordinates are checked to be on or outside of the outlet planes. If this condition is met the current time $\left(t_{c}\right)$ is increased by the time spent in the heat exchangers $\left(t_{\mathrm{HE}}\right)$ and is resampled at the inlet planes. If the $t_{c}$ is less than $t_{e}$, the $t_{c}$ is increased by time step (dt) and the loop is repeated. In the other case final precursor coordinates are recorded and new neutron is processed. The schematic of the process is shown in Figure 3.1.



Figure 3.1. SERPENT extension schematic 
The methodology was used in order to estimate flow rate dependent delayed neutron fraction remaining in the core and the average neutron generation lifetime that allowed to account for power changes during coupled calculations.

\subsection{Coupling neutronics and thermal-hydraulics}

For the thermal-hydraulics analysis the OpenFOAM CFD Toolbox was chosen. A bash script was created in order to communicate the data between SERPENT and OpenFOAM (see Figure 3.2). Coupled codes allowed calculating temperature variations caused by changes in fuel salt flow rate.

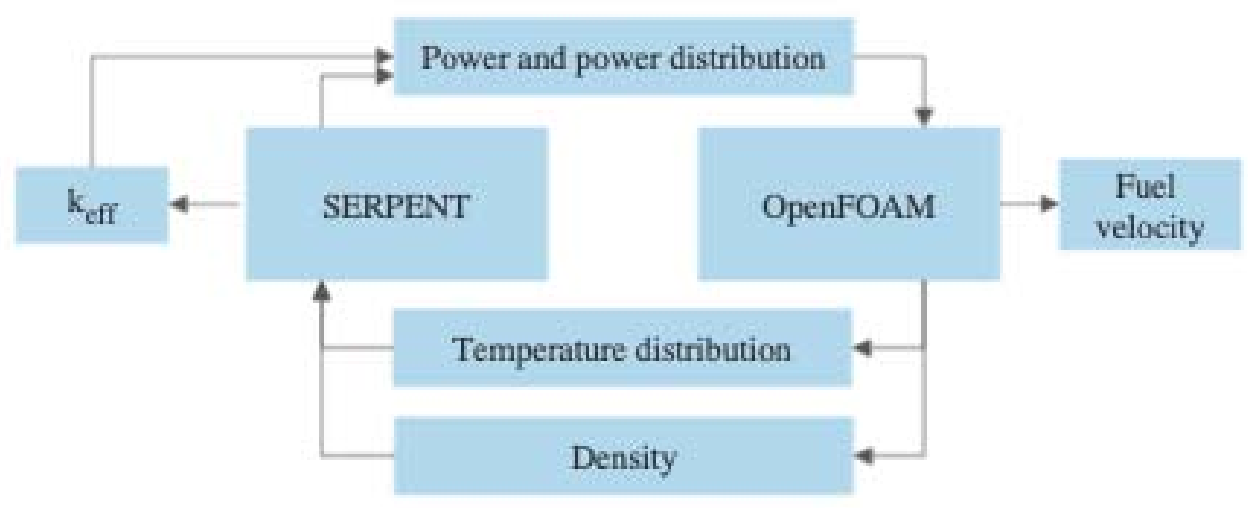

Figure 3.2 Schematic iteration scheme for SERPENT and OpenFOAM coupling

The SERPENT code allows calculating power distribution that is normalised to a set value; therefore the model was modified in order to account for changes in power due to reactivity insertion. The calculations considered the influence on reactor period of variation in delayed neutron population with the flow rate. The power is assumed to be equal to

$$
P=P_{0} \cdot e^{\frac{\delta k_{e f f}}{l} t},
$$

where: P - reactor power, P0 - reference reactor power ( $3 \mathrm{GWth}), \delta$ keff - change in keff (multiplication factor), 1 - average neutron generation lifetime, $\mathrm{t}$ - time during which changes are observed (step length, $0.025 \mathrm{~s})$.

\subsection{Assumptions}

The work is performed under the following set assumptions:

- The fuel salt inlet temperature was calculated based on the average outlet temperature and flow rate;

- The heat transmitted from the fuel salt is $3 \mathrm{GWth}$;

- If the outlet temperature and the flow rate are not sufficient to provide $3 \mathrm{GWth}$, the inlet temperature is assumed to be $850 \mathrm{~K}$, above the melting temperature of the fuel salt ( $~ 823 \mathrm{~K})$ [9] (in a real system this temperature can be sustained by additional heating to prevent fuel solidification);

- The specific heat capacity was assumed to be constant $\left(c_{p}=1391 \mathrm{~J} / \mathrm{kgK}\right)$, due to the lack of data for the fuel salt in operating the temperature range [16]; 
- Considering removal of gaseous fission products decay heat contributes $\sim 2.5 \%$ in the core and $2.5 \%$ in the heat exchangers. Temperature increase due to the decay heat was calculated assuming a continuous and uniform heat distribution across the fuel salt volume.

\section{ANALYSIS}

The analysis consisted of two main parts. The first part focused on estimation of steady state temperatures and $k_{\text {eff }}$ for a varied flow rate and constant (fresh) fissile inventory. The second part analysed reactor behaviour with fuel burnup.

The steady state temperature distribution was first calculated for the normal operating conditions (further referred to as nominal flow rate). Using the result as a reference point, inlet and outlet temperatures were calculated for a range of different flow rates, from 0.1 to 1.3 of nominal flow rate. The analysis also considered if $3 \mathrm{GWth}$ power output could be sustained with the considered flow rates.

In order to assess the effect for a varied fissile inventory content burnup calculations were performed. The composition of the fuel salt was recorded for several time steps. Coupled calculations were repeated for these steps and the equilibrium inlet and outlet temperatures were recorded. The analysis considered the influence of flow rate variation on the core temperatures and $\mathrm{k}_{\text {eff. }}$.

\section{RESULTS AND DISCUSSION}

\subsection{Flow rate influence on operating temperatures}

The influence of flow rate on $\mathrm{k}_{\mathrm{eff}}$ and the fuel inlet and outlet temperatures is presented in Figure 5.1. It can be seen that, assuming a constant transition of $3 \mathrm{GWth}$ in the heat exchangers, at higher flow rates the difference in temperatures between the outlet and the inlet is lower than for the low flow rates. The core stabilises critical for varied flow rates with constant inventory.

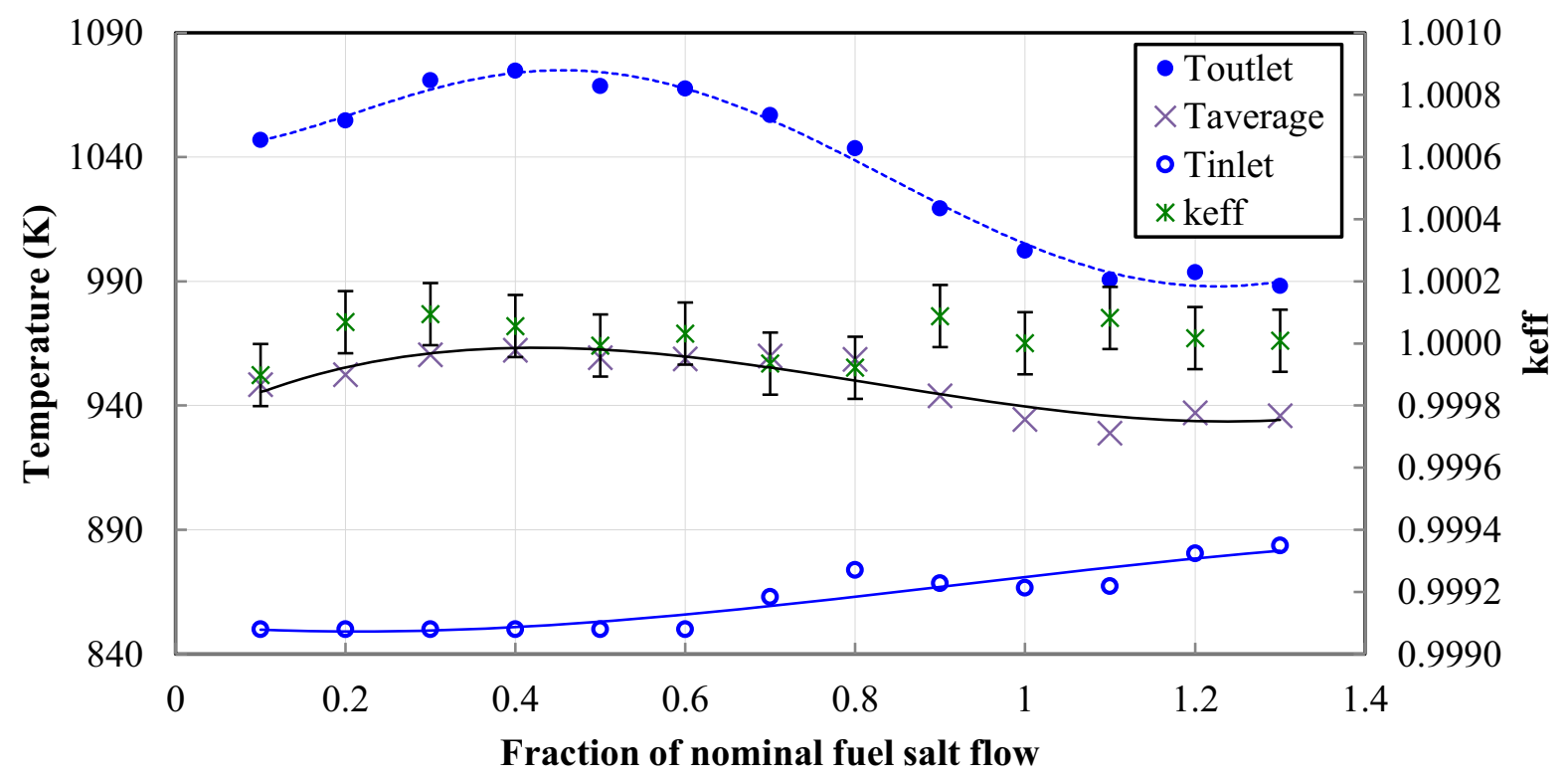

Figure 5.1. Flow rate, outlet temperature and $k_{\text {eff }}$ dependence 
The dependency between the flow rate and the output power is shown on Figure 5.2. With the fresh fuel the power of the core can be sustained at nominal level for the flow rates in the range of 0.7-1.3, as shown on Figure 5.2. At flow rates lower than 0.7 the power output is lower than $3 \mathrm{GW}$ th despite the higher outlet temperatures. This is caused by the assumptions made that inlet temperature cannot fall below $850 \mathrm{~K}$. At lower flow rates constant inlet temperature of $850 \mathrm{~K}$ leads to an increase in average core temperature, which causes the suppression of $\mathrm{k}_{\text {eff }}$ due to negative temperature coefficient, resulting in power reduction and a consequent reduction of the outlet temperature.

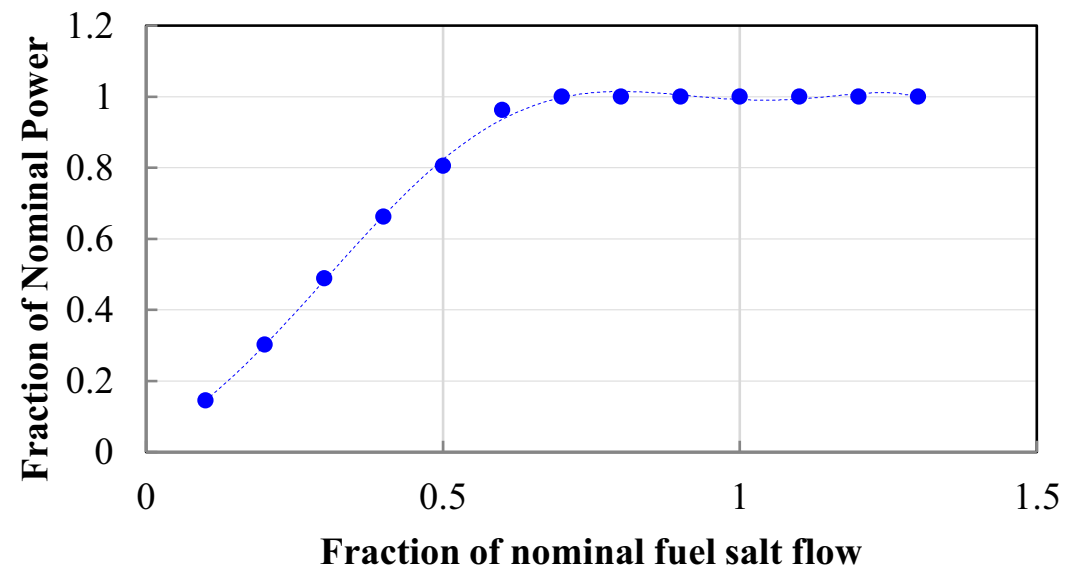

Figure 5.2. Flow rate influence on output power

\subsection{Burnup influence on operating temperatures}

The MSFR has a negative temperature coefficient that has been calculated for the range of $850 \mathrm{~K}$ to $1100 \mathrm{~K}$ as $k_{T}=-12.434 \mathrm{pcm} / \mathrm{K}$. While some yield is present during the burnup, after 100 days of operation the fissile inventory content is reducing linearly resulting in a decrease in $\mathrm{k}_{\text {eff. }}$ This is followed by a consequent reduction in power, then a decrease in average fuel temperature and an increase in $\mathrm{k}_{\text {eff }}$ and in power. This results in a gradual average fuel temperature decrease with the burnup if no fresh fissile material is introduced.

The flow rate was increased by $30 \%$ in order to mitigate inlet temperature reaching its freezing point ( $838 \mathrm{~K}$ [9]). This resulted in the reduction of the outlet temperature and an increase in the inlet temperature while average fuel temperature continued to decrease. The equilibrium temperatures were obtained for several consequent steps until inlet temperatures dropped to $850 \mathrm{~K}$, as shown on Figure 5.3. An increase in flow rate results in the lower outlet temperature and higher values of inlet temperature. Hence, with an increase in the flow rate it is possible to increase the inlet temperature while sustaining average fuel temperature and core criticality. In case of MSFR increasing fuel inlet temperature allows sustaining the core critical for more than 390 EFPD longer before the critical inlet temperature drops to the salt's freezing point. This can prevent the fuel salt from solidification when insertion of fresh fuel and fuel reprocessing are not available. 


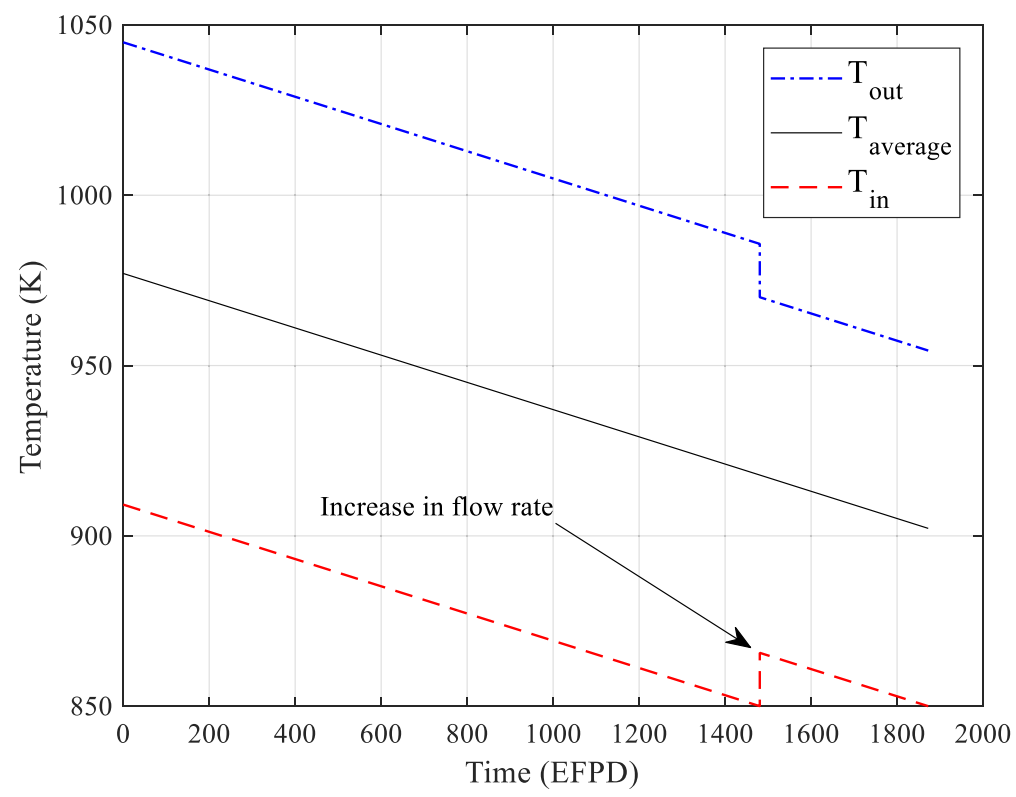

Figure 5.3. Fuel temperature variation vs EFPD at constant power of 3 GWth for the MSFR

Since the MSFR design proposes one pump to be located at each of the 16 heat exchanger loops, control of the reactor can be performed without any additional equipment apart from the design's built-in pumps. The core temperature control can be achieved by switching on and off one or several pumps or varying pumps' power. The flow rate can also be controlled by any mechanical variation in the flow rate through the core, including but not limited to rate control valves, flow diverters, channel size variations, etc.. The same control mechanism could be applied to any circulating fuel reactor.

\section{CONCLUSIONS}

Controlling an MSR by varying the flow rate of the fuel salt can enable a smooth variation in reactivity insertion that allows extending fuel operating lifetime. This control method can also prevent the fuel salt from solidifying by keeping it critical when fuel reprocessing or insertion of new fissile material is not available. In a MSFR the system is capable of sustaining constant power output for the flow rates between 0.7-1.3 of nominal flow rate. This control system does not require any additional equipment; however it requires the core to have negative temperature coefficient and the fuel salt pumps to be capable to operate at various flow rates.

\section{FURTHER WORK}

The methodology can be improved by introducing a detailed decay heat distribution using the technique applied to delayed neutron precursors. The accuracy of results can be improved by considering temperature dependency of the specific heat capacity.

Further work is required to assess operating conditions of the secondary circuit. This analysis will require consideration of the heat exchanger design and the heat exchanger coefficient. Maximum flow rate will be limited by available pumping power, therefore consideration of the pump design will identify operational boundaries for this method.

A separate model representing salt solidification would allow assessing system behavior in close to solidification conditions. 


\section{ACKNOWLEDGMENTS}

The authors would like to thank Rolls Royce for providing the financial support for this work as well as for the fruitful discussions and support in filing a patent.

\section{REFERENCES}

[1] D. E. Holcomb, G. F. Flanagan, B. W. Patton, J. C. Gehin, R. L. Howard, and T. J. Harrison, Fast Spectrum Molten Salt Reactor Options, no. July. 2011.

[2] M. W. Rosenthal, P. R. Kasten, and R. B. Briggs, "Molten-Salt Reactors - History, Status, and Potential," Nucl. Appl. Technol., vol. 8, p. 107, 1969.

[3] J. Serp et al., "The molten salt reactor (MSR) in generation IV: Overview and perspectives," Prog. Nucl. Energy, vol. 77, pp. 308-319, 2014.

[4] V. Ignatiev, "Developing the Next Generation of Molten Salt Reactor Systems in Russian Federation." Kurchatov Institute, 2016.

[5] R. Yoshioka and I. Thorium, "MSR-FUJI Design and MSR-related Activity in Japan," pp. 1-61, 2016.

[6] D. Zhimin, Z. Yang, and C. Kun, “Thorium Molten Salt Reactors (TMSR) Development in China."

[7] D. Journ, "Helium bubbling in a Molten Salt Fast Reactor," 2014.

[8] N. P. Finkelstein and V. M. Lovell, "Fundamental studies of the flotation process: the work of the National Institute for Metallurgy," J. South African Inst. Min. Metall., no. July, p. 15, 1972.

[9] S. Delpech et al., "Reactor physic and reprocessing scheme for innovative molten salt reactor system," J. Fluor. Chem., vol. 130, no. 1, pp. 11-17, 2009.

[10] J. L. Kloosterman, "Safety assessment of the molten salt fast reactor (SAMOFAR)," pp. $0-5,2017$.

[11] M. Aufiero, A. Cammi, C. Fiorina, J. Leppänen, L. Luzzi, and M. E. Ricotti, “An extended version of the SERPENT-2 code to investigate fuel burn-up and core material evolution of the Molten Salt Fast Reactor," J. Nucl. Mater., vol. 441, no. 1-3, pp. 473486, 2013.

[12] M. Aufiero et al., "Development of an OpenFOAM model for the Molten Salt Fast Reactor transient analysis," Chem. Eng. Sci., vol. 111, pp. 390-401, 2014.

[13] A. Laureau, D. Heuer, P. R. Rubiolo, M. Allibert, and M. Aufiero, "Transient coupled calculations of the Molten Salt Fast Reactor using the Transient Fission Matrix approach," vol. 316, pp. 112-124, 2017.

[14] J. Leppänen, "Serpent - a continuous-energy \{Monte Carlo\} reactor physics burnup calculation code," vol. 2014, no. 1/10, 2013.

[15] M. Aufiero et al., "Calculating the effective delayed neutron fraction in the Molten Salt Fast Reactor : Analytical, deterministic and Monte Carlo approaches," Ann. Nucl. Energy, vol. 65, pp. 78-90, 2014.

[16] H. Rouch et al., "Preliminary thermal-hydraulic core design of the Molten Salt Fast Reactor (MSFR)," Ann. Nucl. Energy, vol. 64, pp. 449-456, 2014. 